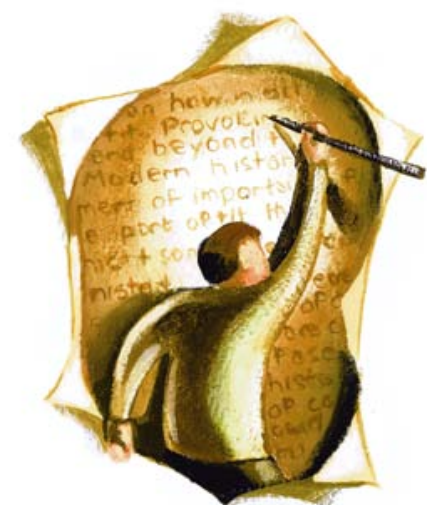

\section{Rosiglitazone and}

\section{macular edema}

As noted in Box I in the article by Claire Kendall and Eric Wooltorton, ${ }^{1}$ long-standing diabetes mellitus, poor diabetes control and insulin therapy are by themselves risk factors for macular edema. Furthermore, only I of the 9 cases of visual impairment reported in Canada for patients taking rosiglitazone was clearly associated with macular edema, and in that case the problem was resolved by discontinuation. The questions thus arise of whether macular edema (especially if it is asymptomatic) is an absolute contraindication to rosiglitazone therapy and whether every patient with diabetes must be subjected to ophthalmologic evaluation before starting this drug.

Although adverse symptoms may diminish upon discontinuation of rosiglitazone, the potential for loss of glycemic control must also be considered. In such situations, what is the risk-benefit ratio for continuation of rosiglitazone therapy, especially if good glycemic control has been achieved?

Perhaps there is a role for "drug holidays" with rosiglitazone. In this regard, macular edema induced by latanoprost, echothiophate iodide or nicotinic acid is usually reversible upon discontinuation of the drug, ${ }^{2}$ which can be reintroduced later.

Systemic factors that may contribute to the progression of diabetic macular edema are blood glucose control, hy- pertension, nephropathy and proteinuria. It has been suggested that use of an angiotensin-converting enzyme (ACE) inhibitor be considered for patients with diabetic retinopathy and nephropathy. ${ }^{3}$ ACE inhibitors are already indicated for microalbuminuria of diabetes, but it is not known whether they would be beneficial in preventing macular edema as well.

\section{Gurusamy Sivagnanam}

School of Medicine

Asian Institute of Medicine, Science and Technology

Kedah, Malaysia

\section{REFERENCES}

I. Kendall C, Wooltorton E. Rosiglitazone (Avandia) and macular edema. $C M A J 2006 ; 174(5): 623$.

2. Roth DB. Nonpseudophakic cystoid macular edema [Internet]. In: eMedicine.com. [place unknown]: WebMD; updated 2005 May I3. Available: www.emedicine.com/oph/topic638.htm (accessed 2006 May 2).

3. Chang S. Recent developments in the treatment of diabetic macular edema. Proceedings of IIth International Conference on Health Problems Related to the Chinese; 2002 May 25-26; New York. p. 2527. Available: www.fcmsdocs.org/Conference/Irth /Diabetic\%20Macular\%20Edema.pdf (accessed 2006 May 2).

DOI:I0.1503/cmaj.1060089

\section{SMART therapy}

The Salmeterol Multicenter Asthma Research Trial (SMART) ${ }^{1}$ reinforces important lessons regarding the appropriate use of long-acting $\beta$-agonists. The trial was stopped early because of increased hazard of asthma, respiratory death or life-threatening events in the salmeterol arm. Eric Wooltorton's Health and Drug Alert ${ }^{2}$ based on data from this study warns physicians of this hazard but fails to put the results in the context of the greater body of research examining the role of longacting $\beta$-agonists in asthma.

Studies examining the use of these drugs in combination with inhaled corticosteroids have consistently demonstrated benefit, with significant reductions in severe asthma exacerbations. ${ }^{3-6}$ Furthermore, the SMART trial failed to show a significant hazard in patients using inhaled corticosteroids at baseline. Despite this, Wooltorton discounts the role of inhaled corticosteroids as a determinant of outcome, stating "Although there is interest in attributing differences in outcomes to differences in baseline rates of inhaled corticosteroid use at enrolment, the trials were not adequately designed to assess this."

Although this statement is true, the message is not. The Canadian asthma consensus guidelines, ${ }^{7}$ in agreement with recommendations worldwide, emphasize the need for adequate antiinflammatory therapy before starting add-on treatment, including longacting $\beta$-agonists. This was not the case in the SMART trial.

Administration of long-acting $\beta$ agonists in combination with inhaled corticosteroids, preferably in a single inhalation device, remains the most effective strategy for prevention of severe asthma exacerbations in those with persistent disease. If we are to reduce asthma morbidity and mortality, it is critical for this message to be understood by clinicians and not confused by reports of inappropriate use.

\section{Alan Bell \\ Department of Family and Community Medicine \\ Humber River Regional Hospital \\ Toronto, Ont. \\ Member \\ Canadian Asthma Consensus \\ Guideline Committee \\ R. Andrew McIvor \\ Professor of Medicine \\ McMaster University \\ Ontario Chair \\ Canadian Asthma Consensus \\ Guideline Committee}

\section{REFERENCES}

I. Nelson HS, Weiss ST, Bleecker ER, et al; SMART Study Group. The Salmeterol Multicenter Asthma Research Trial: a comparison of usual pharmacotherapy for asthma or usual pharmacotherapy plus salmeterol. Chest 2006; I29(I):15-26.

2. Wooltorton E. Long-acting $\beta_{2}$-agonists in asthma: safety concerns. CMAJ 2005;173(9):1030-I.

3. Bateman ED, Boushey HA, Bousquet J, et al; GOAL 